\title{
Effect of Fluconazole and Terbinafine on the Activities of Lanosterol $14 \alpha$-Demethylase and Squalene Epoxidase in Ergosterol Biosynthetic Pathway
}

\author{
M.A. Sayed", T. M. A. Abdel-Rahman', H. M. Hassaneen², \\ A. A. El Kholy ${ }^{3}$ and R. M. Naguib ${ }^{4}$ \\ ${ }^{1}$ Botany Department, Faculty of Science, ${ }^{2}$ Chemistry Department, \\ Faculty of Science, ${ }^{3}$ Clinical Pathology, Faculty of Medicine, \\ and ${ }^{4}$ Microanalytical Center, Faculty of Science, Cairo \\ University, Giza, Egypt.
}

\begin{abstract}
THE ACTIVITIES of the ergosterol biosynthetic enzymes, lanosterol $14 \alpha$-demethylase and squalene epoxidase were assayed by measuring the ergosterol content of $C$. albicans cell membrane under different antifungal drug treatments as compared to control. The ergosterol was measured using the spectrophotometric sterol quantification method. Fluconazole (lanosterol $14 \alpha$ demethylase inhibitor) and terbinafine (squalene epoxidase inhibitor) inactivate both enzymes and stopped the ergosterol biosynthesis completely in susceptible isolates of $C$. albicans. Partial inhibition was observed in resistant isolates of $C$. albicans. Combined mixture of fluconazole (FLU) with terbinafine (TRB) acted synergistically on the ergosterol biosynthetic enzymes leasing to disappearance of the 4peaked curve characteristic to ergosterol.
\end{abstract}

Keywords: Candida albicans, Lanosterol $14 \alpha$-demethylase, Squalene epoxidase, Antifungal drugs, Ergosterol.

Ergosterol is the predominant sterol in fungal plasma membranes; it is important for membrane integrity, for activity of many membrane-bound enzymes and it serves as a bioregulator of fungal membrane fluidity and integrity (Ghannoum and Rice., 1999).

Ergosterol was isolated by multi level extraction associated with saponification and analyzed by reverse phase high performance liquid chromatography (Lavová et al. 2013).

Commonly used antifungal drugs inhibit sterol biosynthesis (azoles, allylamines and morpholines), directly interact with the cell membrane (polyenes) or target cell wall biosynthesis (echinocandins) (Casalinuovo et al., 2004). The annual death rate due to candidiasis was steady between 1950 and about 1970. Since 1970, this rate increased significantly in association with several changes in medical practice, including more widespread use of therapies 
that depress the immune system, the frequent and often indiscriminate use of broad-spectrum antibacterial agents, the common use of indwelling intravenous devices, and the advent of chronic immunosuppressive viral infections such as AIDS. These developments and the associated increase in fungal infections (Beck-Sagué and Jarvis, 1993) intensified the search for new, safer, and more efficient agents to combat serious fungal infections.

The antifungal drugs currently available for the treatment of invasive mycoses can be divided into 4 different classes on the basis of their mechanisms of action: (1) alteration of membrane function (amphotericin B); (2) inhibition of DNA or RNA synthesis (flucytosine); (3) inhibition of ergosterol biosynthesis (terbinafine, fluconazole, itraconazole, and the newer agents voriconazole, posaconazole, and ravuconazole)); and (4) inhibition of glucan synthesis (echinocandins: caspofungin, micafungin, and anidulafungin) (Perea and Patterson, 2002).

The antifungal drugs used are belonging to ten different major groups of substances (Zhang et al., 2007). These are allylamines, benzofurans, echinocandins, hydroxypyridones, imidazoles, morpholines, polyenes, pyrimidines, thiocarbamates and triazoles (Polak, 1988; Bohme \& Karthaus, 1999). Most therapies, designed to treat fungal infections, target the ergosterol biosynthesis pathway or its end product, ergosterol, a membrane sterol that is unique to fungi. It is the main sterol, and thus is necessary for growth and normal membrane function of fungal cell (Lupetti et al., 2002).

Clinical resistance is classically defined as persistence or progression of an infection despite the administration of appropriate antimicrobial treatment. The prediction of the clinical outcome for a patient with a mycotic infection is often a difficult question-and one in which many factors intervene. The antifungal susceptibility of the fungal isolate is only one of the elements that contribute to clinical resistance; other factors include the pharmacokinetics of the antifungal drug used, host factors, the site of infection, and the fungal pathogen itself. In general, fungi can be intrinsically resistant to antifungal drugs (primary resistance) or can develop resistance in response to exposure to the drug during treatment (secondary resistance) (Perea and Patterson, 2002).

The newer antifungals have been effective in the treatment of systemic fungal infections and offer a potent alternative to potentially toxic amphotericin B therapy (Lewis \& Klepser, 1999). It is well documented, however, that several pathogenic yeasts have either intrinsic or acquired resistance to the azole antifungal drugs (Rex et al., 1995). It is advisable, therefore, to determine the antifungal susceptibility patterns of microbial isolates, which may assist in making appropriate decisions regarding the best therapeutic option (Pfaller et al., 1997).

Infections by Candida albicans and related fungal pathogens pose a serious health problem for immune compromised patients. Azole drugs, the most common agents used to combat infections, target the sterol biosynthetic pathway (Gallo-Ebert et al., 2013). Candida infections can be spread to vulnerable Egypt. J. Bot., 54, No. 2 (2014) 
people with depressed immune systems who are in the hospital, where the fungus is commonly found on the hands of care givers and where indwelling catheters can allow an infection to take hold. The number of available drugs for the treatment of systemic fungal infections is limited. The antifungals known nowadays can be classified into azolic and polienics. The azolics are elected in the first instance for treating these diseases and are generally fungistatics, while the latter are fungicides. In recent years, the terbinafine, amphotericin B and azoles mainly ketoconazole, fluconazole and itraconazole have been the drugs of choice in therapy (Goodman and Gilman, 1996).

Fluconazole is a member of azoles family that targets essential enzyme lanosterol 14a-demethylase (Erg11) (Song, et al., 2004). Terbinafine is a member of allylamines family it has specific mechanism on squalene epoxidase (Graminha et al., 2004). Inhibition of both enzymes which are essential in ergosterol biosynthesis in C. albicans is considered as a mode of control of the serious candidiasis disease. Hence, the objective of this study was focused at studying the disorders induced in ergosterol biosynthetic enzymes under antifungal treatments using $C$. albicans isolates screened from immunocompromized childrens suffering from Candidiasis.

\section{Candida albicans}

\section{Material and Methods}

Isolates were screened from blood, urine and sputum of immunocompromized children hospitalized in Abo El-Reesh pediatric Hospital, Cairo University. They all suffer from candidiasis. C. albicans isolates were distinguished into white and opaque isolates and identified by germ tube method and API (Naguib, 2013).

\section{Determination of MIC90}

Mic90 values were determined by Mohsen et al. (2013) in the previous paper.

Ergosterol assay by spectrophotometric method

The enzyme activities were assayed by quantitative determination of membrane ergosterol, spectrophotometrically, in antifungal treated C. albicans isolates as compared with control. The method of Arthington-Skaggs et al. (1999) was adopted.

A single $C$. albicans colony from an overnight Sabouraud dextrose agar (SDA) plate culture was used to inoculate $50 \mathrm{ml}$ of Sabouraud dextrose broth containing $0,0.25,0.5,1 \times \mathrm{xMIC}_{90} \mu \mathrm{g} / \mathrm{ml}$ of each antifungal (Breivik and Owades, 1977). The cultures were incubated for $16 \mathrm{hr}$ with shaking $(150 \mathrm{rpm})$ at $35^{\circ} \mathrm{C}$. The stationaryphase cells were harvested by centrifugation at $2700 \mathrm{rpm}$ (HERAEUS LABOFUGE 200 centrifuge) for $5 \mathrm{~min}$ and washed once with sterile distilled water. The net wet weight of the cell pellets was determined. Three milliliters of $25 \%$ alcoholic potassium hydroxide solution $(25 \mathrm{~g}$ of $\mathrm{KOH}$ and $35 \mathrm{ml}$ of sterile distilled water, 
brought to $100 \mathrm{ml}$ with $100 \%$ ethanol), was added to the pellets and vortex mixed for $1 \mathrm{~min}$. Cell suspensions were transferred to a clean $16 \mathrm{~mm}$ borosilicate glass screwcap tube and were incubated in an $85^{\circ} \mathrm{C}$ water bath for $1 \mathrm{hr}$. Following incubation, tubes were allowed to cool to room temperature. Sterols were then extracted by addition of a mixture of $1 \mathrm{ml}$ of sterile distilled water and $3 \mathrm{ml}$ of $\mathrm{n}$-heptane followed by vigorous vortex mixing for $3 \mathrm{~min}$. The $\mathrm{n}$-heptane layer was transferred to a clean borosilicate glass screw-cap tube and stored at $-20^{\circ} \mathrm{C}$ for as long as $24 \mathrm{hr}$ prior to analysis, a $20 \mathrm{ml}$ aliquot of sterol extract was diluted five fold in 100\% ethanol and scanned spectrophotometrically between 240 and $300 \mathrm{~nm}$ with a Gilford Response Spectrophotometer (SHIMADZU UV-1650PC).

The presence of ergosterol and the late sterol intermediate 24(28) Dehydroergosterol [24(28) DHE)] in the extracted sample resulted in a characteristic four-peaked curve. The absence of detectable ergosterol in extracts was indicated by a flat line. Any dose-dependent activity lead to decrease in the height of the absorbance peaks which corresponded to decreased ergosterol concentration due to inhibition in both lanosterol $14 \alpha$-demethylase and squalene epoxidase activities. Ergosterol content was calculated as a percentage of the wet weight of the cell by the following equations:

1: \% ergosterol $+\% 24(28) \mathrm{DHE}=\left[\left(\mathrm{A}_{281.5} / 290\right) \times \mathrm{F}\right] /$ pellet weight

2:\% 24(28) $\mathrm{DHE}=\left[\left(\mathrm{A}_{230} / 518\right) \times \mathrm{F}\right] /$ pellet weight,

$\%$ ergosterol $=1-2$

Where $\mathrm{F}$ is the factor for dilution in ethanol and 290 and 518 are the E values (in percentages per centimeter) determined for crystalline ergosterol and 24(28) DHE, respectively.

\section{Statistical analysis}

Duncan test was executed to show homogeneity among the means at $(P<0.05)$. Statistical analyses were performed using SPSS software (version 15; SPSS, Chicago, IL).

\section{Results}

Ergosterol percentage in the membrane of $C$. albicans isolates treated with FLU.

The data in Table 1 clearly indicate that the wet weight decreased as a function of fluconazole concentration in all isolates, but was more drastically in the susceptible isolates.

The data in Table 2 evidently indicated that FLU treatment completely inhibited ergosterol biosynthesis in the susceptible isolates (white \& opaque). In resistant isolates, the white form of $C$. albicans showed a partial inhibition at the low concentration of FLU $\left(0.25 \mathrm{xMIC}_{90}\right)$, then complete inhibition in ergosterol biosynthesis at the higher concentrations was observed. Opaque resistant isolate showed a dose-dependent inhibition in ergosterol biosynthesis due to partial inactivation of lanosterol $14 \alpha$-demethylase. This indicated fungistatic effect of fluconazole.

Egypt. J. Bot., 54, No. 2 (2014) 
TABLE 1. Effect of different fluconazole concentrations on the wet weight of $C$. albicans isolates .

\begin{tabular}{|c|c|c|c|c|}
\hline \multirow{3}{*}{ FLU conc. } & \multicolumn{4}{|c|}{ Wet weight } \\
\hline & \multicolumn{2}{|c|}{ Resistant } & \multicolumn{2}{|c|}{ Susceptible } \\
\hline & White & Opaque & White & Opaque \\
\hline Control & $0.4861 \pm 0.10^{\mathrm{b}}$ & $0.5746 \pm 0.13^{b}$ & $0.4261 \pm 0.07^{\mathrm{c}}$ & $0.6136 \pm 0.15^{\mathrm{c}}$ \\
\hline $0.25 \times M^{2} C_{90}$ & $0.3356 \pm 0.13^{b}$ & $0.2894 \pm 0.16^{\mathrm{a}}$ & $0.3123 \pm 0.05^{\mathrm{b}}$ & $0.3092 \pm 0.19^{b}$ \\
\hline $0.5 \times M_{1} C_{90}$ & $0.1430 \pm 0.09^{\mathrm{a}}$ & $0.2535 \pm 0.17^{a}$ & $0.1757 \pm 0.05^{a}$ & $0.2423 \pm 0.04^{\mathrm{ab}}$ \\
\hline 1xMIC90 $_{90}$ & $0.0834 \pm 0.02^{\mathrm{a}}$ & $0.2293 \pm 0.09^{a}$ & $0.1435 \pm 0.06^{\mathrm{a}}$ & $0.0128 \pm 0.00^{\mathrm{b}}$ \\
\hline $\begin{array}{c}\text { Values of } \\
\mathrm{MIC}_{90}\left(\mu \mathrm{g} \mathrm{ml}^{-1}\right)\end{array}$ & 200 & 76 & 15 & 6.5 \\
\hline
\end{tabular}

TABLE 2. Percentage of ergosterol in C. albicans isolates treated with FLU .

\begin{tabular}{|c|c|c|c|c|}
\hline \multirow{2}{*}{ FLU conc. } & \multicolumn{4}{|c|}{ \% of ergosterol } \\
\cline { 2 - 5 } & \multicolumn{2}{|c|}{ Resistant isolate } & \multicolumn{2}{c|}{ Susceptible isolate } \\
\cline { 2 - 5 } & White & Opaque & White & Opaque \\
\hline Control & $0.0102 \pm 0.01^{\mathrm{a}}$ & $0.0118 \pm 0.00^{\mathrm{c}}$ & $0.0184 \pm 0.00$ & $0.0183 \pm 0.01$ \\
\hline $0.25 \mathrm{xMIC} 90$ & $0.0082 \pm 0.00^{\mathrm{a}}$ & $0.0033 \pm 0.00^{\mathrm{ab}}$ & -- & -- \\
\hline $0.5 \mathrm{xMIC} 90$ & -- & $0.0045 \pm 0.00^{\mathrm{b}}$ & -- & -- \\
\hline $1 \times$ XIC 90 & -- & $0.0016 \pm 0.00^{\mathrm{a}}$ & -- & -- \\
\hline
\end{tabular}

Mean \pm SD, $n=3$. Across the same column, means with the same letter(s) are not significantly different at $P>0.05$, whereas those with different letters are significantly different at $P<0.05$.

Table 3 reveals that the wet weight decreased with increased TRB concentrations with more prominent reduction in the susceptible forms.

TABLE 3. Effect of different terbinafine concentrations on the wet weight of $C$. albicans isolates .

\begin{tabular}{|c|c|c|c|c|}
\hline \multirow{3}{*}{ TRB conc. } & \multicolumn{4}{|c|}{ Wet weight } \\
\hline & \multicolumn{2}{|c|}{ Resistant } & \multicolumn{2}{|c|}{ Susceptible } \\
\hline & White & Opaque & White & Opaque \\
\hline Control & $0.5795 \pm 0.05^{b}$ & $0.5364 \pm 0.04^{\mathrm{b}}$ & $0.3649 \pm 0.17^{\mathrm{b}}$ & $0.7519 \pm 0.00^{\circ}$ \\
\hline $0.25 \times M^{2} C_{90}$ & $0.2433 \pm 0.06^{\mathrm{a}}$ & $0.4299 \pm 0.08^{\mathrm{b}}$ & $0.1217 \pm 0.02^{\mathrm{a}}$ & $0.1287 \pm 0.03^{\mathrm{b}}$ \\
\hline $0.5 \times M^{2} C_{90}$ & $0.2346 \pm 0.10^{\mathrm{a}}$ & $0.2854 \pm 0.06^{\mathrm{a}}$ & $0.1512 \pm 0.01^{\mathrm{a}}$ & $0.0994 \pm 0.01^{\mathrm{b}}$ \\
\hline 1xMIC90 $_{9}$ & $0.1835 \pm 0.02^{\mathrm{a}}$ & $0.1891 \pm 0.03^{\mathrm{a}}$ & $0.0306 \pm 0.01^{\mathrm{a}}$ & $0.0478 \pm 0.02^{\mathrm{a}}$ \\
\hline $\begin{array}{l}\text { Values of MIC }{ }_{90} \\
\left(\mu \mathrm{g} \mathrm{ml}^{-1}\right)\end{array}$ & 450 & 56 & 5 & 0.6 \\
\hline
\end{tabular}

In the FLU-susceptible opaque isolate, Fig. 1 Reveals that curve a (control; 0.0 FLU) gave the four-peaked curve characteristic for ergosterol biosynthesis. When concentration of FLU increased, the peaks disappeared; indicating inhibition of ergosterol biosynthesis due to inhibition in lanosterol $14 \alpha$ - 
demethylase activity. At concentration $0.25 \times \mathrm{MIC}_{90}$ (curve b), there was a minor peak; then all peaks were totally disappeared in treatment $0.5 \times \mathrm{MIC}_{90}$ (curve c). The flat line $\mathrm{d}$ in treatment with $1 \mathrm{xMIC}_{90}$, indicated undetectable ergosterol content.

In case of FLU-susceptible white isolate, Fig. 2 indicated that curve a (control; 0.0 FLU) gave the four-peaked curve typical to ergosterol biosynthesis. The peaks disappeared completely (flat lines b, c, and d) at all concentrations of FLU, indicating the blockage in ergosterol biosynthesis.

In case of FLU-resistant opaque isolate, Fig. 3 revealed that curves (a, b, c and d) gave the typical four-peaked curves characteristic to the ergosterol biosynthesis. This indicated that FLU at all concentrations did not affect ergosterol biosynthesis as well as the lanosterol $14 \alpha$-demethylase activity.

In case of FLU-resistant white $C$. albicans isolate, Fig. 4 showed that the control (curve a, 0.0 FLU) and $0.25 \times \mathrm{MIC}_{90}$ treatment (curve b) showed the fourpeaked curves typically relevant to ergosterol biosynthesis. As concentration of FLU increased, the peaks disappeared. In treatment with $0.5 \mathrm{xMIC}_{90}$ two minor peaks were evident (curve c), then all peaks were totally abolished in a FLU concentration of $1_{\mathrm{xMIC}} \mathrm{M}_{90}$ which resulted in a flat line $\mathrm{d}$. This dose-dependent decrease indicated partial inhibition of lanosterol $14 \alpha$-demethylase.

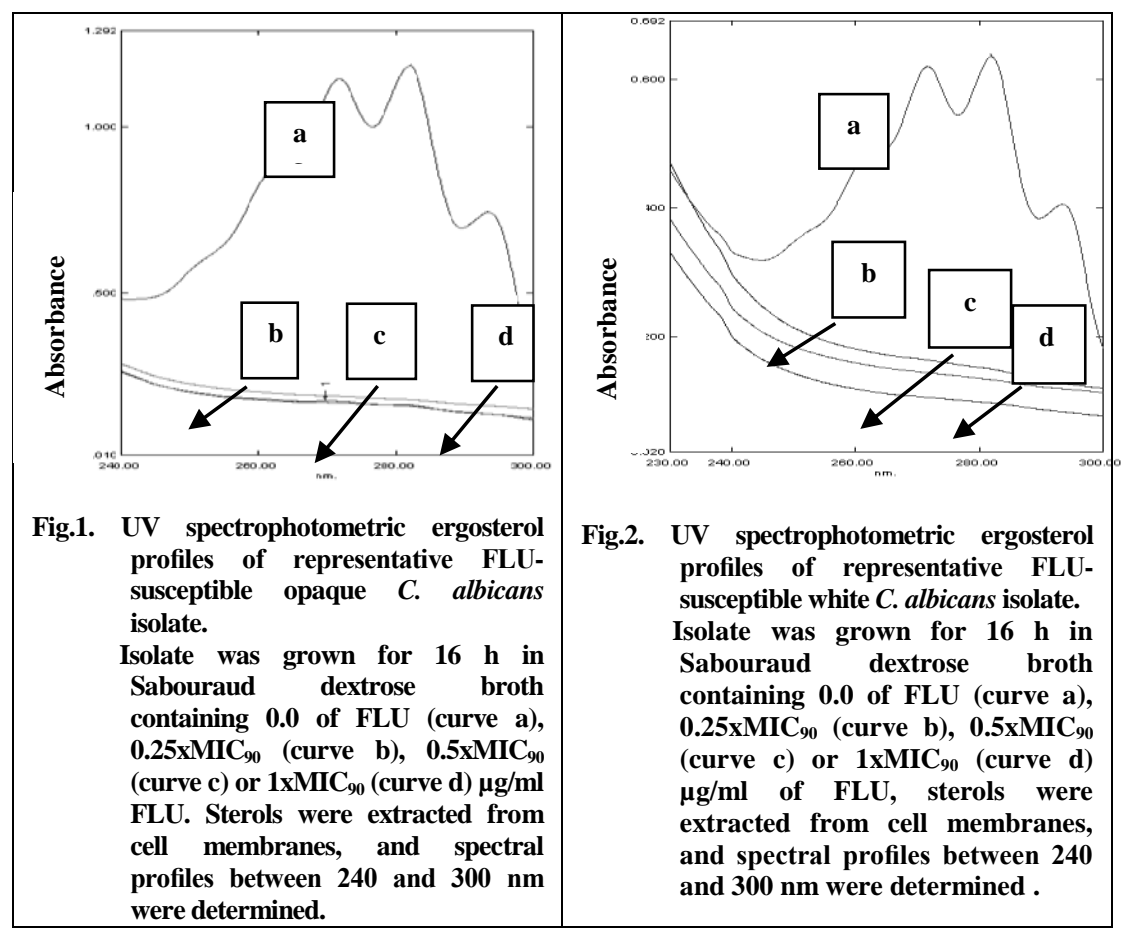

Egypt. J. Bot., 54, No. 2 (2014) 


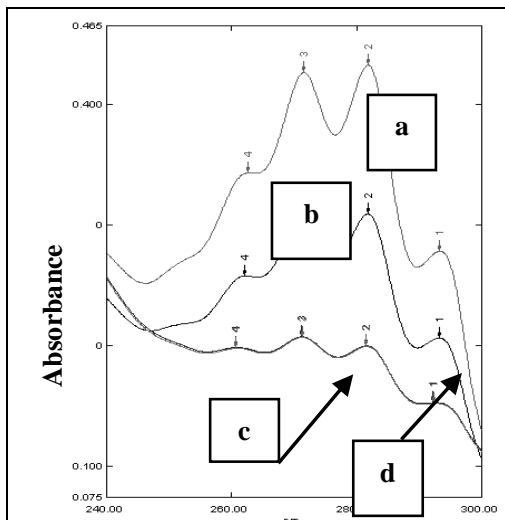

Fig. 3. UV spectrophotometric ergosterol profiles of representative FLU resistant opaque $C$. albicans isolate. Isolate was grown for $16 \mathrm{~h}$ in Sabouraud dextrose broth containing 0.0 of FLU (curve a), $0_{0.25} x$ IC $_{90}$ (curve b), $0.5 \times$ MIC $_{90}$ (curve c) or $\mathbf{1 x M I C}_{90}$ (curve d) $\mu \mathrm{g} / \mathrm{ml}$ FLU. Sterols were extracted from cell membranes, and spectral profiles between 240 and $300 \mathrm{~nm}$ were determined.

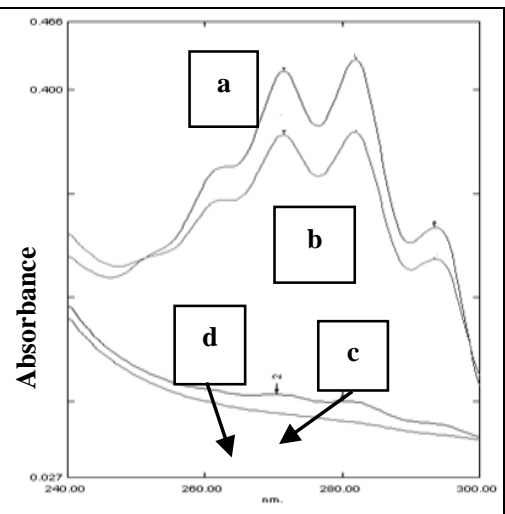

Fig. 4. UV spectrophotometric ergosterol profiles of representative FLUresistant white $C$. albicans isolate. Isolate was grown for $16 \mathrm{~h}$ in Sabouraud dextrose broth containing 0.0 of FLU (curve a), $0^{25} \mathrm{xMIC}_{90}$ (curve b), $\mathrm{0.5x} \mathrm{MIC}_{90}$ (curve c) or $1^{1 \times M I C}{ }_{90}$ (curve d) $\mu \mathrm{g} / \mathrm{ml}$ of FLU, sterols were extracted from cell memberanes, and spectral profiles between 240 and $300 \mathrm{~nm}$ were determined.

Ergosterol percentage in the membrane of C. albicans isolates treated with the squalene inhibitror TRB

The data in Table 4 showed that TRB efficiently inhibit the ergosterol biosynthesis in $C$. albicans susceptible-isolates either white or opaque. In case of resistant isolates, the ergosterol biosynthesis appeared to be slightly affected by $\mathrm{TRB}$ at all concentrations. It is worth noting that TRB treatment, at $0.25 \mathrm{MIC}_{90}$, of resistant white isolate increased the ergosterol biosynthesis indicating its high resistance to the TRB antifungal drug.

TABLE 4. Percentage of ergosterol in C. albicans isolates treated with TRB .

\begin{tabular}{|c|c|c|c|c|}
\hline \multirow{2}{*}{ TRB conc. } & \multicolumn{4}{|c|}{ \% of ergosterol } \\
\cline { 2 - 5 } & \multicolumn{2}{|c|}{ Resistant } & \multicolumn{2}{c|}{ Susceptible } \\
\cline { 2 - 5 } & White & Opaque & White & Opaque \\
\hline Control & $0.0256 \pm 0.00^{\mathrm{b}}$ & $0.0464 \pm 0.06^{\mathrm{a}}$ & $0.016967 \pm 0.02$ & $0.0122 \pm 0.00$ \\
\hline $0.25 \times \mathrm{MIC}_{90}$ & $0.0313 \pm 0.00^{\mathrm{c}}$ & $0.0109 \pm 0.01^{\mathrm{a}}$ & -- & -- \\
\hline $0.5 \times M I C_{90}$ & $0.0192 \pm 0.00^{\mathrm{a}}$ & $0.0102 \pm 0.01^{\mathrm{a}}$ & -- & -- \\
\hline $1 \times \mathrm{XIC} 90$ & $0.0183 \pm 0.00^{\mathrm{a}}$ & $0.0100 \pm 0.01^{\mathrm{a}}$ & -- & -- \\
\hline
\end{tabular}

Mean $\pm \mathrm{SD}, \mathrm{n}=3$. Across the same column, means with the same letter are not significantly different at $P>0.05$, whereas those with different letters are significantly different at $P<0.05$. 
In case of TRB-susceptible opaque isolate (Fig. 5) shows that the control; 0.0 TRB (curve a) displayed the four-peaked curve characteristic to ergosterol biosynthesis. As the concentration of TRB increased, the peaks disappeared. In treatment with $0.25 \mathrm{xMIC}_{90}$ (curve b) three minor peaks were evident, but with $0.5 \times \mathrm{MIC}_{90}$ treatment (curve c) only one minor peak was apparent, then all peaks completely disappeared with concentration of $1 \mathrm{xMIC}_{90}$ (curve $\mathrm{d}$ ). These results indicated that applying TRB with the mentioned doses resulted in high disturbances in squalene epoxidase activity which reflected decrease in ergosterol concentrations.

In comparing the susceptibilities of the isolate opaque-susceptible to either FLU or TRB it was found that at all FLU concentrations used, flat-lines corresponded to block in ergosterol content were evident (Fig. 1). While, in case of treatment with TRB; disturbances in ergosterol was dose dependent (Fig. 5). These results suggested that FLU is more effective than TRB against $C$. albicans.

In case of TRB-susceptible white isolate (Fig. 6) showed that only the control (curve a; $0.0 \mathrm{TRB}$ ) displayed the typical four-peaked profile for ergosterol biosynthesis. As the concentration of TRB increased, two minor peaks were observed as shown in curves $\mathrm{b}$, $\mathrm{c}$, and $\mathrm{d}$ for the treatments $0.25 \mathrm{xMIC}_{90}, 0.5 \times \mathrm{MIC}_{90}$, and $1 \mathrm{xMIC}_{90}$, respectively. This indicated high disturbance and decrement in ergosterol content at all TRB concentrations compared to the control.

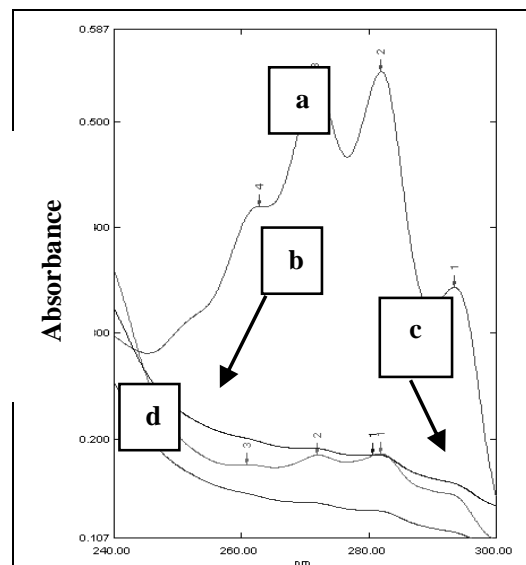

Fig. 5. UV spectrophotometric ergosterol profiles of representative TRBsusceptible opaque $C$. albicans isoate. Isolate was grown for $16 \mathrm{~h}$ in Sabouraud dextrose broth containing 0.0 of TRB (curve a), $\mathbf{0 . 2 5 x M I C}_{90}$ (curve b), $0.5 \times \mathrm{XIC}_{90}$ (curve c) or $1 \mathrm{xMIC}_{90}$ (curve d) $\mu \mathrm{g} / \mathrm{ml}$ TRB. Sterols were extracted from cell membranes, and spectral profiles between 240 and $300 \mathrm{~nm}$ were determined.

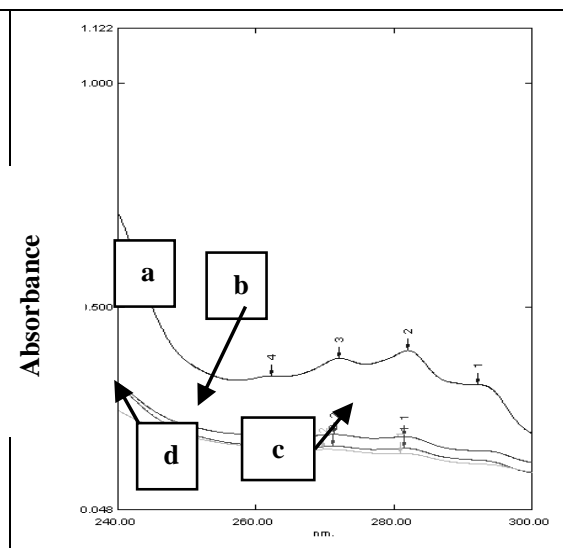

Fig. 6. UV spectrophotometric ergosterol profiles of representative TRBsusceptible white $C$. albicans isolate. Isolate was grown for $16 \mathrm{~h}$ in Sabouraud dextrose broth containing 0.0 of TRB (curve a), $0_{0.25} \mathrm{XIC}_{90}$ (curve b), 0.5xMIC ${ }_{90}$ (curve c) or $1 \mathrm{xMIC}_{90}$ (curve d) $\mu \mathrm{g} / \mathrm{ml}$ of TRB, sterols were extracted from cell memberanes, and spectral profiles between 240 and $300 \mathrm{~nm}$ were determined.

Egypt. J. Bot., 54, No. 2 (2014) 
In TRB-resistant opaque C. albicans isolate (Fig. 7) it was found that treatments with $\mathrm{TRB}$, except $1 \times \mathrm{xMIC}_{90}$, resulted in ergosterol biosynthesis characteristic four-peaked curves. As the concentration of TRB increased the height of peaks decreased. At $1 \mathrm{xMIC}_{90}$ treatment (curve d), only two peaks were displayed. This suggests the corruption in ergosterol biosynthesis as a result of partial inhibition in squalene epoxidase at highest concentration of TRB $\left(1 \mathrm{xMIC}_{90}\right)$.

In case of TRB-resistant white $C$. albicans isolate (Fig. 8) revealed that all concentrations of TRB had no effect on ergosterol biosynthesis and typical fourpeaked curves characteristic to ergosterol content were detected indicating that squalene epoxidase activity in this starin was not inhibited by TRB.

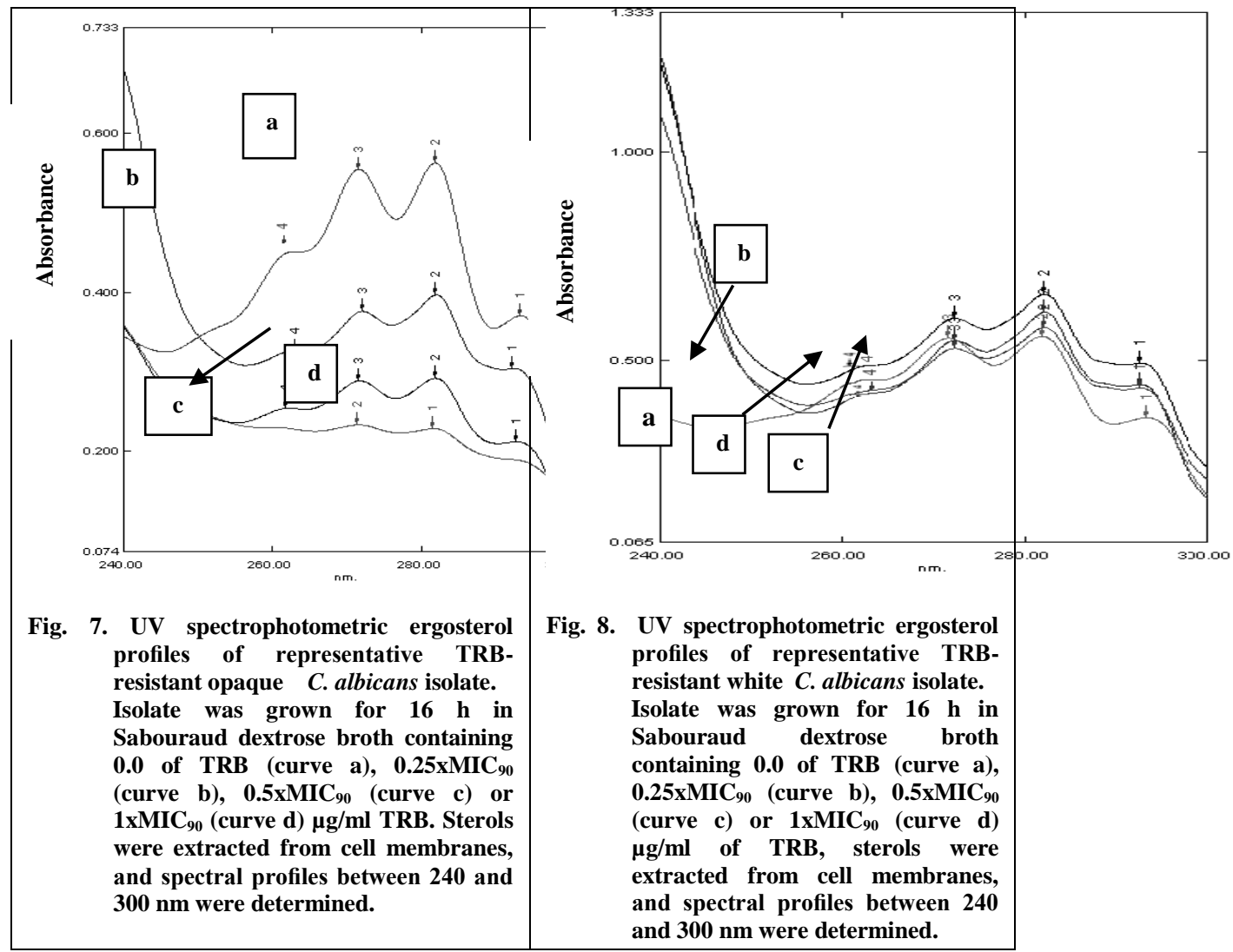

Egypt. J. Bot., 54, No. 2 (2014) 


\section{Discussion}

Ergosterol, a membrane sterol, unique to fungi, is necessary for growth and normal membrane function in fungal cells. Besides its role in memberane fluidity, asymmetry and integrity, it contributes to proper function in membrane bound enzymes (Lupetti et al., 2002 and Lopes et al., 2013)). Fluconazole (azole compound) targets the ergosterol biosynthesis enzyme (Erg11) lanosterol 14 $\alpha$ demethylase and are widely applied class of antifungal agents because of their wide spectrum of activity (Onyewu, et al., 2003). Terbinafine is an antifungal belonging to the allylamine class of synthetic antifungal agents (Petranyi, et al., 1984). It inhibits another biosynthesis enzyme (Erg1) squalene epoxidase.

A unique and ergosterol indicative spectral absorption four-peaked curve was produced between 240-300 $\mathrm{nm}$. The sterol quantitation method (SQM) based on measuring of ergosterol and dehydroergosterol (late sterol pathway intermediate) contents were used (Arthington-Skaggs et al., 1999; Aijaz et al., 2010 and Phin, 2012).

In the present study, SQM was used to evaluate the effect of antifungal drugs (FLU and TRB) on C. albicans isolates. This method discriminates between the activity of lanosterol $14 \alpha$-demethylase and squalene epoxidase under different treatments. It was found that a typical 4-peaked curve was detected in absence of antifungals (controls). FLU and TRB inhibited the ergosterol biosynthesis due to inhibition of ergosterol biosynthetic enzymes in susceptible isolates of $C$. albicans (white and opaque forms). TRB partially inhibited ergosterol biosynthetic enzyme; squalene epoxidase in the resistant white and opaque isolates in a dose-dependent manner. FLU inhibited the ergosterol biosynthetic enzyme, lanosterol $14 \alpha$-demethylase in resistant white isolates, while, it partially inhibited the enzyme activity in the opaque resistant isolates.

Arthington-Skaggs et al. (1999) used SQM to test 38 isolates of susceptible, dose-dependent susceptible and resistant $C$. albicans against FLU. 18 susceptible isolates showed significant reduction in ergosterol content, in dose-dependent manner. They concluded that SQM discriminated between resistant, highly resistant and susceptible isolates indicating that it may predict clinical outcome more accurately.

Azole drugs inhibit ergosterol biosynthesis in fungal cells by binding to their cytochrome P-450 sterol 14 $\alpha$-demethylase (Erg11) (Vanden Bossche et al., 1983; Song et al., 2004 and Warrilow et al., 2012). Voriconazole is 1.6 and 160-fold more active than FLU in inhibiting ergosterol P-450 dependent $14 \alpha$-demethylase in C. albicans and Aspergillus fumigatus lysate, respectively. Three general mechanisms of azole resistance have been described by $C$. albicans: i] alteration of the target enzyme 14a-demythelase (Lamb et al., 1997; White, 1997; Sanglard et al., 1998), ii] decreasing alteration in the drug uptake or efflux (Parkinson, 1996; Sanglard et al., 1995), iii] deficiency of sterol desaturase which suppresses the accumulation of toxic intermediates (Geber et al., 1995; Kelly et al., 1997).

Egypt. J. Bot., 54, No. 2 (2014) 
Onyewu et al. (2003) claimed that azoles target ergosterol biosynthetic enzyme lanosterol $14 \alpha$-demethylase and are a widely applied class of antifungal agents because of their broad therapeutic window, wide spectrum of activity and low toxicity. They established that drugs targeting other enzymes in the ergosterol biosynthetic pathway (terbinafine and fenpropimorph) also exhibit dramatic synergistic antifungal activity against wild-type $C$. albicans when used in combination.

C. albicans, growth inhibition with TRB appears to result from the ergosterol deficiency resulting from the non competitive inhibition in squalene epoxidase (Erg1), an essential enzyme in ergosterol biosynthesis. The fungal death is caused by the accumulation of high levels of intracellular squalene, probably in combination with ergosterol deficiency as a result of terbinafine-induced inhibition of squalene peroxidase. He also reported that ergosterol deficiency is not the primary cause of death (the azoles inhibit ergosterol biosynthesis that result in ergosterol deficiency but are primary fungistatic in action) this suggested that squalene accumulation rather than ergosterol deficiency is the key to the fungicidal action of terbinafine (Ryder, 1992).

Terbinafine acts by blocking fungal ergosterol biosynthesis via inhibition of squalene epoxidase (Ryder et al., 1984; Graminha et al., 2004 and Shahnaz et al., 2013). It was reported that the antifungal activity of terbinafine is based on the inhibition of fungal ergosterol at the point of squalene epoxidation resulting in accumulation of intracellular squalene which is fungicidal to dermatophytic yeasts (Ryder and Troke, 1981; Paltauf et al., 1982; Ryder, 1985; Ryder and Dupont, 1985; Ryder, 1992). It is suggested that inhibition of ergosterol biosynthesis may render the $C$. albicans memberanes susceptible to further damage, indicating direct damage of squalene epoxidase with inhibitors such as terbinafine and noftafine (Georgopapadakou and Bertasso, 1992).

Allylamine and azoles are synthetic antifungal agents which inhibits ergosterol biosynthesis. Allylamines inhibit ergosterol biosynthetic pathway at the level of squalene epoxidase causing the accumulation of squalene (Melloni et al., 1974; Bianchi et al., 1977; Georgopoulos et al., 1981; Paltauf et al., 1982; Ryder and Troke, 1981; Morita and Nozawa, 1985; Ryder et al., 1986) These compounds are highly fungicidal against dermatophytes (Ganzinger et al., 1986; Goodfield et al., 1989). The azole antifungal inhibits ergosterol biosynthesis at the level of $\mathrm{C} 14$ demethylase and is clinically useful as broad-spectrum antifungal agents (Berg et al., 1986; Fromtling, 1988). Terbinafine have little or no activity against $C$. albicans in yeast form, although filamentous form is susceptible (Schaude et al., 1987).

Docking studies followed by molecular dynamic simulation and quantum interaction energy calculations resulted in identification of the terbinafine- 
squalene mode of action. The terbinafine lipophitic moiety is located vertically inside the squalene epoxidase binding pocket with the test - butyl group oriented toward its center. Such a position result in conformational changes in squalene epoxidase and prevents the natural substrate from being able to bind to the enzyme's active site (Nowosielski et al., 2011)

\section{References}

Aijaz, A., Amber, K., Nikhat, M., and Luqman, A.K. (2010) Evolution of ergosterol biosynthesis inhibitors as fungicidal against Candida. Microb. Pathog., 48, 35-41.

Arthington-Skaggs, B.A, Jradi, H., Desai, T., and Morrison, C.J. (1999) Quantitation of ergosterol content: novel method for determination of fluconazole susceptibility of Candida albicans. J. Clin. Microbiol., 37, 3332-3337.

Beck-Sagué, C., and Jarvis, W.R. (1993) Secular trends in the epidemiology of nosocomial fungal infections in the United States, 1980-1990. National Nosocomial Infections Surveillance System. J. Infect. Dis., 167, 1247-1251.

Berg, D., Buchel, K.H., Plempel, M., and Regel, E. (1986) Antimycotic sterol biosynthesis inhibitors. Trends Pharmacol. Sci., 7, 233-238.

Bianchi, A., Monti, G., and de Carneri, I. (1977) Tolciclate: further antimycotic studies. Antimicrob. Agents Chemother., 12, 429-430.

Bohme, A., and Karthaus, M. (1999) Systemic fungal infections in patients with hematologic malignancies: indications and limitations of the antifungal armamentarium. Chemotherapy, 45, 315-324.

Breivik O. N. and Owades J L. (1977) Spectrophotometric semi-microdetermination of ergosterol in yeast. Agric. Food Chem., 5, 360-363.

Casalinuovo, I.A., Di Francesco, P., and Garaci, E. (2004) Fluconazole resistance in Candida albicans: a review of mechanisms. Eur. Rev. Med. Pharmacol. Sci., 8, 69-77.

Fromtling, R.A. (1988) Overview of medically important antifungal azole derivatives. Clin. Microbiol. Rev., 1, 187-217.

Gallo-Ebert, C., M. Donigan; I. L. Stroke, R. N. Swanson, M. T. Manners, J. Francisco, G. and Toner, et al. (2013). Novel Antifungal Drug Discovery Based On Targeting Pathways Regulating the Fungal-Conserved Upc2 Transcription Factor. Antimicrob. Agent Chemother., 57(12), [Epub ahead of print]

Ganzinger, U., Stutz, A., Petranyi, G. and Stephen, A. (1986) Allylamines: topical and oral treatment of dermatomycoses with a new class of antifungal agents. Acta Dermato-Venereol., 121, 155-160.

Geber, A., Hitchcock, C.A., Swartz, J.E., Pullen, F.S., Marsden, K.E., Kwon-Chung, K.J. and Bennett, J.E. (1995) Deletion of the Candida glabrata ERG3 and ERG11

Egypt. J. Bot., 54, No. 2 (2014) 
genes: effect on cell viability, cell growth, sterol composition, and antifungal susceptibility. Antimicrob. Agents Chemother, 39, 2708-2727.

Georgopapadakou, N.H., and Bertasso, A. (1992) Effects of Squalene Epoxidase Inhibitors on Candida albicans. Antimicrob. Agents Chemother, P.1779-1781.

Georgopoulos, A., Petranyi, G., Mieth, H. and Drews, J. (1981) In vitro activity of naftifine, a new antifungal agent. Antimicrob. Agents Chemother, 19, 386-389.

Ghannoum, M.A. and Rice, L.B. (1999) Antifungal agents: mode of action, mechanisms of resistance, and correlation of these mechanisms with bacterial resistance. Clin. Microbiol. Rev., 12, 501-517.

Goodfield, M.J.D., Powell, N.R., Forster, R.A., Evans, E.G.V. and Raven, A. (1989) Treatment of dermatophyte infections of the finger- and toe-nails with terbinafine (SF86-327, Lamisil) an orally active fungicidal agent. Br. J. Dermatol., 121, 753-757.

Goodman, L.S. and Gilman A. (1996) "As Bases Farmacológicas da Terapêutica". 9.ed., Rio de Janeiro: McGraw-Hill; 1996.

Graminha, M.A., Rocha, E.M., Prade, R.A. and Martinez-Rossi, N.M. (2004) Terbinafine resistance mediated by salicylate 1-monooxygenase in Aspergillus nidulans. Antimicrob. Agents Chemother., 48, 3530-3535.

Kelly, S.L., Lamb, D.C., Kelly, D.E., Manning, N.J., Loeffler, J., Hebart, H., Schunacher, U. and Einsele, E. (1997) Resistance to fluconazole and crossresistance to amphotericin B in Candida albicans from AIDS patients caused by defective sterol delta 5,6-desaturation. FEBS Lett., 400, 80-82.

Lamb, D.C., Kelly, D.E., Schunck, W.H., Shyadehi, A.Z., Akhtar, M., Lowe, D.J., Baldwin, B.C. and Kelly, S.L. (1997) The mutation T315A in Candida albicans sterol $14 \alpha$-demethylase causes reduced enzyme activity and fluconazole resistance through reduced affinity. J. Biol. Chem., 272, 5682-5688.

Lavová, B., Hároniková, A., Márová, I. and Urminská, D. (2013) Production of ergosterol by Saccharomyces cerevisiae. J. Microbiol. Biotech. Food Sci., 2(1), 1934-1940.

Lewis, R. E. and Klepser, M. E. (1999) The changing face of nosocomial candidemia: epidemiology, resistance, and drug therapy. Amr. J. Health Syst. Pharm., 56, 525-533.

Lopes, G. Pinto, E., Andrade, P.B. and Valentão, P. (2013) Antifungal activity of phlorotannins against dermatophytes and yeasts: Approaches to the mechanism of action and influence on Candida albicans Virulence Factor. PLoS ONE, 8(8), e72203.

Lupetti, A., Danesi, R., Campa, M., Del Tacca, M. and Kelly, S. (2002) Molecular basis of resistance to azole antifungals. Trends Mol., Med., 8, 76-81.

Egypt. J. Bot., 54, No. 2 (2014) 
Melloni, P., Metelli, R., Vecchietti, V., Logemann, W., Castellino, S., Monti, G. and de Carneri, I. (1974) New antifungal agents. Eur. J. Med. Chem., 9, 26-31.

Mohsen, A., S.Tahany, M.A., Abdel-Rahman, Hamdi, M. H.Amany, A. El kholy and Rash, M. Naguib. (2013) Gene expression in antifungal resistant and susceptible isolates of Candida albicans. Egypt. J. Bot., (accepted for publication on 22/11/2013).

Morita, T. and Nozawa, Y. (1985) Effects of antifungal agents on ergosterol biosynthesis in Candida albicans and Trichophyton mentagrophytes: differential inhibitory sites of naphthiomate and miconazole. J. Invest. Dermatol., 85, 434-437.

Naguig, R. M. (2013) Functional evaluation of microbial enzymes in drug-resistant yeast. Ph.D. Thesis, Cairo University.

Nowosielski, M., Hoffmann, M., Wyrwicz, L.S., Stepniak, P., Plewczynski, D.M., Lazniewski, M., Ginalski, K. and Rychlewski, L. (2011) Detailed mechanism of squalene epoxidase inhibition by terbinafine. J. Chem. Inf. Model., 51(2), 455-62.

Onyewu, C., Blankenship, J.R., Del Poeta, M. and Heitman, J. (2003) Ergosterol biosynthesis inhibitors become fungicidal when combined with calcineurin inhibitors against Candida albicans Candida glabrata, and Candida krusei. Antimicrob. Agents Chemother, 47(3): 956-964

Paltauf, F., Daum, G., Zuder, G., Hogenauer, G., Schultz, G. and Seidl, G. (1982) Squalene and ergosterol biosynthesis in fungi treated with naftifine, a new antimycotic agent. Biochim. Biophys. Acta, 712, 268-273.

Parkinson A (1996) Biotransformation of xenobiotics. in Casarett \& Doull's Toxicology: "The Basic Science of Poisons, ed Klaassen CD" McGraw-Hill, New York, 5 ed., pp 113-186.

Perea, S. and Patterson, T.F. (2002) Antifungal resistance in pathogenic fungi. Clin.Infect. Dis., 35, 1073-1080.

Petranyi, G., Ryder, N.S. and Stutz, A. (1984) Allylamine derivatives: new class of synthetic antifungal agents inhibiting squalene epoxidase. Science, 224. 1239-1241.

Pfaller M. A., Rex J. H. andRinaldi M. G. (1997) Antifungal susceptibility testing: technical advances and potential clinical applications. Clin. Infect. Dis, 24:776-784.

Phin, C. K. (2012) An evaluation of Ganoderma fungal colonization using ergosterol analysis and quantification. The Planter, 88(1034), 311-319.

Polak, A. (1988) Mode of action of morpholine derivatives. Annl. N.Y. Acad. Sci., 544: 221-228.

Rex, J. H., Cooper, C. H. Jr., Merz, W. G., Galgiani, J. N. and Anaissie, E. J. (1995) Detection of amphotericin B-resistant Candida isolates in a broth-based system. Antimicrob. Agents Chemother., 39, 906-909.

Egypt. J. Bot., 54, No. 2 (2014) 
Ryder, N.S. (1985) Specific inhibition of fungal sterol biosynthesis by SF 86-327, a new allylamine antimycotic agent. Antimicrob. Agents Chemother, 27, 252-256.

Ryder, N.S. (1992) Terbinafine: Mode of action and properties of the squalene epoxidase inhibition. Br. J. Dermatol., 126 (Suppl. 39), 2-7.

Ryder, N.S. and Dupont, M.C. (1985) Inhibition of squalene epoxidase by allylamine antimycotic compounds. A comparative study of the fungal and mammalian enzymes. Biochem., 230, 765-770.

Ryder, N.S., and Troke, P.F. (1981) The activity of naftifine as a sterol synthesis inhibitor in Candida albicans, p. 1016-1017.

Ryder, N.S., Frank, I., and Dupont, M.C. (1986) Ergosterol biosynthesis inhibition by the thiocarbamate antifungal agents tolnaftate and tolciclate. Antimicrob. Agents Chemother, 29, 858-860.

Ryder, N.S., Seidl, G., and Troke, P. (1984) Effect of the antimycotic drug naftifine on growth of and sterol biosynthesis in Candida albicans. Antimicrob. Agents Chemother, 25, 483-487.

Sanglard, D., Ischer, F., Koymans, L., and Bille, J. (1998) Amino acid substitutions in the cytochrome P-450 lanosterol 14-demethylase (CYP51A1) from azole-resistant Candida albicans clinical isolates contribute to resistance to azole antifungal agents. Antimicrob. Agents Chemother., 42, 241-53.

Sanglard, D., Kuchler, K., Ischer, F., Pagani, J.L., Monod, M., and Bille, J. (1995) Mechanisms of resistance to azole antifungal agents in Candida albicans isolates from AIDS patients involve specific multidrug transporters. Antimicrob. Agents Chemother., 39, 2378-2386.

Schaude, M., Ackerbauer, H., and Mieth. H. (1987) Inhibitory effect of antifungal agents on germ tube formation in Candida albicans. Mykosen., 30(6), 281-287.

Shahnaz, M., Kaura, S. Shubhlata, S. Prasad, D. N. and Dev, D. (2013) Synthesis, characterization and antifungal activity of 1-naphthylmethylamine derivatives. Int. J. Bioassay, 2(10), 1317-1321.

Song, J.L., Harry, J.B., Eastman, R.T., Oliver, B.G. and White, T.C. (2004) The Candida albicans lanosterol 14- $\alpha$-demethylase (ERG11) gene promoter is maximally induced after prolonged growth with antifungal drugs. Antimicrob. Agents Chemother., 48, 1136-1144.

Vanden Bossche, H., Willemsens, G., Cools, W., Marichal, H.P. and Lauwers, W.F.J. (1983) Hypothesis on the molecular basis of the antifungal activity of N-substituted imidazoles and triazoles. Biochem. Soc. Trans., 11, 665-667. 
Warrilow, A. G., Parker, J. E. Kelly, D.E. and S Kelly, S.L. (2012) Azole Affinity of Sterol 14 $\alpha$-Demethylase (CYP51) Enzymes from Candida albicans and Homo sapiens. Antimicrob. Agent Chemother, 57(3), 1352-1360.

White, T.C. (1997) Increased mRNA levels of $E R G 16, C D R$, and $M D R 1$ correlate with increases in azole resistance Candida albicans isolates from a patient infected with human immuno-deficiency virus. Antimicrob. Agents Chemother, 41, 1482-1487.

Zhang, A.Y., Camp, W.L., and Elewski, B.E. (2007) Advances in topical and systemic antifungals. Dermatol. Clin., 25, 165-183.

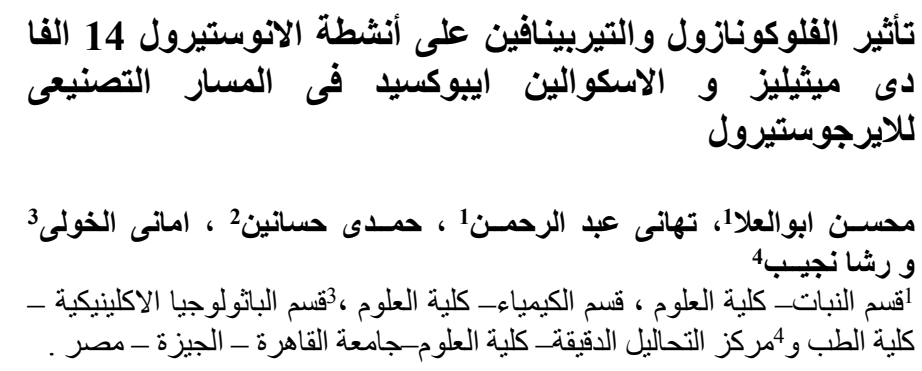

لقد تم دراسة أنشطة إنزيمات التصنيع الحيوى لايرجوستيرول

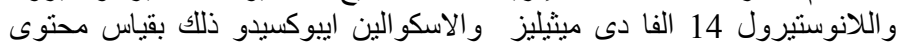

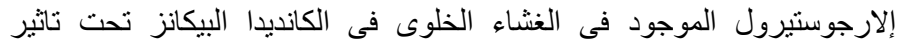

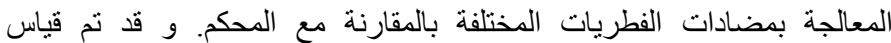

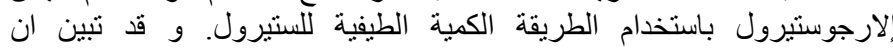

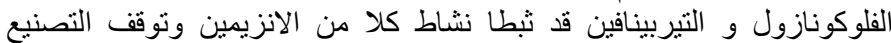

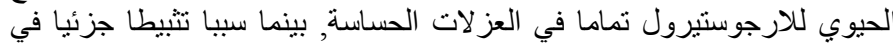

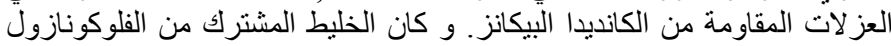

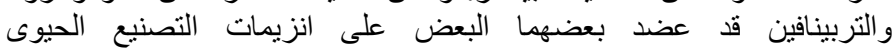

ل الايرجوستثيرول.

Egypt. J. Bot., 54, No. 2 (2014) 